\title{
Disability Outcomes in the N-MOmentum Trial of Inebilizumab in Neuromyelitis Optica Spectrum Disorder
}

Romain Marignier, MD, PhD, Jeffrey L. Bennett, MD, PhD, Ho Jin Kim, MD, PhD, Brian G. Weinshenker, MD, Sean J. Pittock, MD, Dean Wingerchuk, MD, Kazuko Fujihara, MD, Friedemann Paul, MD, Gary R. Cutter, PhD, Ari J. Green, MD, MCR, Orhan Aktas, MD, Hans-Peter Hartung, MD, Fred D. Lublin, MD, Ian M. Williams, PhD, Jorn Drappa, MD, PhD, Dewei She, PhD, Daniel Cimbora, PhD, William Rees, PhD, Michael Smith, PhD, John N. Ratchford, MD, Eliezer Katz, MD, and Bruce A.C. Cree, MD, PhD, MAS, on behalf of the N-MOmentum Study Investigators

Neurol Neuroimmunol Neuroinflamm 2021;8:e978. doi:10.1212/NXI.0000000000000978

\section{Abstract}

\section{Objective}

To assess treatment effects on Expanded Disability Status Scale (EDSS) score worsening and modified Rankin Scale (mRS) scores in the N-MOmentum trial of inebilizumab, a humanized anti-CD19 monoclonal antibody, in participants with neuromyelitis optica spectrum disorder (NMOSD).

\section{Methods}

Adults $(\mathrm{N}=230)$ with aquaporin-4 immunoglobulin G-seropositive NMOSD or -seronegative neuromyelitis optica and an EDSS score $\leq 8$ were randomized (3:1) to receive inebilizumab $300 \mathrm{mg}$ or placebo on days 1 and 15 . The randomized controlled period (RCP) was 28 weeks or until adjudicated attack, with an option to enter the inebilizumab open-label period. Threemonth EDSS-confirmed disability progression (CDP) was assessed using a Cox proportional hazard model. The effect of baseline subgroups on disability was assessed by interaction tests. mRS scores from the RCP were analyzed by the Wilcoxon-Mann-Whitney odds approach.

\section{Results}

Compared with placebo, inebilizumab reduced the risk of 3-month CDP (hazard ratio [HR]: 0.375; 95\% CI: 0.148-0.952; $p=0.0390)$. Baseline disability, prestudy attack frequency, and disease duration did not affect the treatment effect observed with inebilizumab (HRs: 0.213-0.503; interaction tests: all $p>0.05$, indicating no effect of baseline covariates on outcome). Mean EDSS scores improved with longer-term treatment. Inebilizumab-treated participants were more likely to have a favorable mRS outcome at the end of the RCP (OR: 1.663 ; 95\% CI: $1.195-2.385 ; p=0.0023$ ).

\section{Conclusions}

Disability outcomes were more favorable with inebilizumab vs placebo in participants with NMOSD.

\author{
Correspondence \\ Dr. Marignier \\ romain.marignier@chu-lyon.fr
}

\section{MORE ONLINE}

$\rightarrow$ Class of Evidence

Criteria for rating therapeutic and diagnostic studies

NPub.org/coe 


\section{Glossary}

AQP4-IgG = aquaporin-4 immunoglobulin G; CDP = confirmed disability progression; EDSS = Expanded Disability Status Scale; HR = hazard ratio; $\mathbf{m R S}$ = modified Rankin Scale; NESC = Neurostatus e-Scoring; NMOSD = neuromyelitis optica spectrum disorder; NNT = number needed to treat; OLP = open-label period; OSIS = Opticospinal Impairment Scale; PI = principal investigator; $\mathbf{R C P}=$ randomized controlled period; WMWodds = Wilcoxon-Mann-Whitney odds.

\section{Classification of Evidence}

This study provides Class II evidence that for patients with NMOSD, inebilizumab reduces the risk of worsening disability. N-MOmentum is registered at ClinicalTrials.gov: NCT02200770.

Neuromyelitis optica spectrum disorder (NMOSD) is a rare, chronic, autoimmune disorder of the CNS, characterized by a relapsing course of severe attacks of optic neuritis and transverse myelitis; brain, diencephalic, and brainstem lesions occur less commonly. ${ }^{1-4}$ Accrual of severe disability in NMOSD appears to be driven primarily by irreversible attack-related injury, although emerging evidence suggests that subclinical disease processes may be present. ${ }^{5-8}$

Immunosuppression is typically used in NMOSD to reduce the risk of attacks. There are limited data on the effect of drugs used empirically in NMOSD on disability. ${ }^{9} 10$ Eculizumab ${ }^{11}$ and satralizumab ${ }^{12}$ significantly reduced the risk of NMOSD attack, but significant effects on disability-related outcomes were not reported.

B cells have an important role in NMOSD pathogenesis. ${ }^{13,14}$ Inebilizumab, a B-cell-depleting antibody targeting CD19, was evaluated in a randomized, double-blind, placebo-controlled study (N-MOmentum). ${ }^{15}$ Inebilizumab significantly reduced the risk of NMOSD attack and worsening disability, and was associated with fewer new MRI lesions and disease-related hospitalizations. The most common adverse reactions $(\geq 10 \%$ of participants treated with inebilizumab and greater than placebo) were urinary tract infection and arthralgia.

Standard measures of Expanded Disability Status Scale (EDSS) score changes, typically used in studies of MS, use continuous measurement of EDSS with annualized relapse rate as a measure of effect. Such measurements are not possible in the time to event design used in this study, which was required for the ethical use of a placebo control. ${ }^{16}$ Although the initial N-MOmentum study results reported reduced frequency of worsening disability in inebilizumab-treated participants compared with the placebo group, ${ }^{15}$ this article presents detailed, preplanned, and post hoc analyses of disability outcomes, with specific consideration to assessing disability in NMOSD clinical trials.

\section{Methods}

\section{Study Design and Participants}

The N-MOmentum study was an international, randomized, double-blind, placebo-controlled, phase $2 / 3$ trial with an optional open-label extension phase. The study design (including CONSORT flow diagram) was described previously. ${ }^{15}$

In brief, adults (aged $\geq 18$ years) with a diagnosis of NMOSD who had an EDSS score $\leq 8.0$ and a history of either at least 1 attack in the previous year or at least 2 attacks in the previous 2 years were eligible. A single reference laboratory (Mayo Clinic, Rochester, MN) determined aquaporin-4 immunoglobulin G (AQP4-IgG) status. Both AQP4-IgG-seropositive and -seronegative patients were enrolled; AQP4-IgG-seronegative patients needed to meet the 2006 neuromyelitis optica diagnostic criteria, ${ }^{17}$ verified by an eligibility committee.

Following screening, eligible participants were randomized (3:1) to IV inebilizumab $300 \mathrm{mg}$ or placebo (saline) administered on days 1 and 15 of the randomized controlled period (RCP). Use of other immunosuppressants was prohibited during the study. Participants continued in the RCP for up to 28 weeks or until occurrence of an adjudicated attack, at which point they had the option to transition to the open-label extension.

Enrollment was stopped after 230 participants were randomized and dosed, based on recommendation from the Independent Data Monitoring Committee due to clear evidence of inebilizumab efficacy.

\section{Standard Protocol Approvals, Registrations, and Patient Consents}

The N-MOmentum trial is registered at ClinicalTrials.gov (NCT02200770). The study was conducted in accordance with the International Conference on Harmonisation Guidelines for Good Clinical Practice and the principles of the Declaration of Helsinki in its currently applicable version. An institutional review board or ethics committee at each study site approved the protocol. Written informed consent was obtained from all participants.

\section{Outcome Measures}

Disability was assessed using the EDSS ${ }^{18}$ and the modified Rankin Scale (mRS). ${ }^{19}$ A qualified, independent rater using the Neurostatus e-Scoring (NESC) system performed the 
EDSS assessment. EDSS assessments were conducted within 5 days of the report of a potential attack. NESC is an electronic data capture, analysis, and management system developed at the University of Basel to improve consistency and reduce measurement noise for the EDSS. ${ }^{20}$ An integrated algorithm provides real-time feedback to flag potential inconsistencies in the final EDSS score, which can then be resolved by the EDSS assessor. EDSS scores were assessed at baseline, at RCP weeks 12 and 28, every 3 months in the open-label period (OLP), and at any attack assessment visit for new or worsening NMOSD symptoms.

The study investigator evaluated the $\mathrm{mRS}$ score at baseline, at RCP weeks 4, 8, 12, 16, 22, and 28, and at any assessment visit for new or worsening NMOSD symptoms. The mRS score ranges from 0 (no symptoms) to 6 (dead) (appendix e-1, links.lww.com/NXI/A454), and changes in $\mathrm{mRS}$ score were assessed from baseline to the last RCP visit.

Attack severity was graded according to a modified version of the Opticospinal Impairment Scale (OSIS), ${ }^{21,22}$ which characterizes attacks as major or minor based on changes in domain-specific scores for neurologic function. Attack recovery assessment was performed 28 days after the attack and was graded according to change in the same domain-specific scores relative to the score at the time of attack. Details of the scale and scoring are provided in appendix e-2, links.lww. com/NXI/A454.

\section{Statistical Analyses}

Analyses were performed for the intent-to-treat population, defined as study participants who were randomized and received any study medication. All analyses were prespecified before unblinding of the data, unless specifically described as post hoc.

The proportion of participants with disability worsening from baseline, based on EDSS score, was compared between treatment groups by logistic regression analysis, with treatment, baseline EDSS score, and AQP4-IgG serostatus as explanatory variables. Missing values were considered as worsening. The last RCP visit was at 28 weeks for those without an adjudicated attack or at the time of attack assessment for those who did experience an adjudicated attack. Disability worsening at any visit, whether scheduled or as part of an attack assessment, was defined according to the increase in the EDSS score from the participant's baseline score $(\geq 2$ points from a baseline of 0 ; $\geq 1$ point from a baseline of 1-5; and $\geq 0.5$ points from a baseline of $\geq 5.5$ ).

Three post hoc analyses of EDSS data were performed to address specific limitations of the study design and answer additional questions. For the post hoc analyses, a 3-month period was defined in each analysis variant as the time from attack to the assessment of EDSS score. Treatment allocation was respected in all cases. To mitigate concern that analysis of EDSS worsening at the last RCP visit could be compromised with EDSS values recorded in the setting of an acute attack visit, the first post hoc analysis substituted data from OLP month 3 as the final EDSS assessment time point. This was done for participants who experienced an adjudicated attack at their last RCP visit; the end of the RCP (week 28) was retained for participants who did not experience an adjudicated attack. This analysis allowed all participants to be evaluated at a time point when they were not experiencing an acute attack.

The second post hoc analysis evaluated the proportion of participants with EDSS score worsening relative to baseline at the end of the RCP (attack assessment, or week 28 for those without an attack) and 3 months later (3-month confirmed disability progression $[\mathrm{CDP}])$. The purpose of this analysis was to assess concern of a lack of longitudinal confirmation of EDSS change by analyzing the proportion of participants with 3-month CDP from the end of the RCP, regardless of attack occurrence.

The third analysis evaluated 3-month CDP at any time during the RCP. The purpose of this analysis was to not limit the analysis to the end of RCP assessment (which is most influenced by attacks) and instead to compare 3-month CDP stemming from any study visit during the RCP, as is traditionally performed in MS clinical trials. If the follow-up EDSS score was missing, the participant was assumed to not have 3-month CDP. The first 2 analyses used logistic regression; the third analysis used the Cox proportional hazard model.

The risk of EDSS score worsening at the end of the RCP was evaluated in prespecified subgroups dichotomized by the baseline EDSS score ( $<5$ vs $\geq 5$; the cutoff at 5 represents the point where disease affects daily activities to a degree that requires special provisions), number of prior NMOSD attacks ( $<2$ vs $\geq 2$; cutoff selected based on the inclusion criteria of attacks in the 2 years before enrollment), and disease duration ( $<5$ vs $\geq 5$ years; the cutoff of 5 years was chosen to represent those with longer-term disease), all characteristics presumed to reflect disease severity. $p$ Values are presented for the interaction test in each case, where $p>0.05$ indicates no statistically significant difference in treatment effect between subgroups. The mean change in EDSS was plotted, with standard error, for the RCP and to month 12 of the OLP.

The last postbaseline mRS scores in the RCP were analyzed using the Wilcoxon-Mann-Whitney odds (WMWodds) approach, where all possible pairs of the between-group difference in $\mathrm{mRS}$ outcomes are compared. ${ }^{23,24}$ This prespecified analysis approach was selected because it requires no assumptions about the distribution of the ordinal outcome data, and it enables a measure of the effect size with CIs. The distribution of mRS scores at baseline and end of the RCP for each treatment group are presented descriptively. The proportion of participants with major or minor attacks was compared between treatment arms using the Fisher exact test. All statistical analyses were performed using SAS version 9.4. 
Table Summary of Baseline Demographics and Characteristics (Intent-to-Treat Population)

\begin{tabular}{|c|c|c|}
\hline Demographic/characteristic & $\begin{array}{l}\text { Placebo } \\
(n=56)\end{array}$ & $\begin{array}{l}\text { Inebilizumab } \\
(n=174)\end{array}$ \\
\hline Age, years, mean (SD) & $\begin{array}{l}42.6 \\
(13.9)\end{array}$ & $43.0(11.6)$ \\
\hline Sex, women & $50(89.3)$ & $159(91.4)$ \\
\hline \multicolumn{3}{|l|}{ Race } \\
\hline American Indian/Alaskan Native & $5(8.9)$ & $14(8.0)$ \\
\hline Asian & $8(14.3)$ & $39(22.4)$ \\
\hline Black or African American & $5(8.9)$ & $15(8.6)$ \\
\hline White & $28(50.0)$ & $92(52.9)$ \\
\hline Other/multiple categories checked & $10(17.9)$ & $14(8.0)$ \\
\hline Disease duration, years, mean (SD) & $2.8(3.5)$ & $2.4(3.3)$ \\
\hline \multicolumn{3}{|l|}{ Disease duration } \\
\hline$<5$ years & $46(82.1)$ & $144(82.8)$ \\
\hline$\geq 5$ years & $10(17.9)$ & $30(17.2)$ \\
\hline \multicolumn{3}{|l|}{ Most recent attack } \\
\hline Optic neuritis & $21(37.5)$ & $85(48.9)$ \\
\hline Myelitis & $34(60.7)$ & 99 (56.9) \\
\hline Brain/brainstem & $10(17.9)$ & $8(4.6)$ \\
\hline $\begin{array}{l}\text { Number of Gd+ lesions at baseline, } \\
\text { mean (SD) }\end{array}$ & $0.9(0.9)$ & $1.2(1.2)$ \\
\hline EDSS score, median (range) & $\begin{array}{l}4.0 \\
(1.0-8.0)\end{array}$ & $3.5(0-8.0)$ \\
\hline
\end{tabular}

\section{EDSS category}

\begin{tabular}{lll}
\hline $\mathbf{0}$ & $0(0.0)$ & $4(2.3)$ \\
\hline $\mathbf{1 - 4 . 5}$ & $40(71.4)$ & $129(74.1)$ \\
\hline $\mathbf{2}$ & $16(28.6)$ & $41(23.6)$ \\
\hline $\mathbf{m R S}$ score, median (range) & $2(0-5)$ & $2(0-5)$ \\
\hline $\mathbf{m R S}$ category & & \\
\hline $\mathbf{0}$ & $2(3.6)$ & $26(14.9)$ \\
\hline $\mathbf{1}$ & $21(37.5)$ & $55(31.6)$ \\
\hline $\mathbf{2}$ & $17(30.4)$ & $49(28.2)$ \\
\hline $\mathbf{3}$ & $5(8.9)$ & $16(9.2)$ \\
\hline $\mathbf{4}$ & $9(16.1)$ & $26(14.9)$ \\
\hline $\mathbf{5}$ & $2(3.6)$ & $2(1.1)$ \\
\hline
\end{tabular}

Modified Opticospinal Impairment

Scale, median (range)

\begin{tabular}{lll}
\hline Visual acuity & $1.5(1-7)$ & $1(1-6)$ \\
\hline Motor function & $2(0-7)$ & $1(0-7)$ \\
\hline Brain function & $0(0-2)$ & $0(0-4)$ \\
\hline Brainstem function & $0(0-4)$ & $0(0-4)$ \\
\hline
\end{tabular}

Table Summary of Baseline Demographics and Characteristics (Intent-to-Treat Population) (continued)

\begin{tabular}{lll}
\hline Demographic/characteristic & $\begin{array}{l}\text { Placebo } \\
(\mathbf{n}=\mathbf{5 6})\end{array}$ & $\begin{array}{l}\text { Inebilizumab } \\
(\mathbf{n}=\mathbf{1 7 4})\end{array}$ \\
\hline $\begin{array}{l}\text { Modified Opticospinal Impairment Scale } \\
\text { category (with score } \mathbf{3} \text { ), \% }\end{array}$ & \\
\hline Visual acuity & 26.8 & 16.1 \\
\hline Motor function & 28.6 & 27.6 \\
\hline Brain function & 0 & 0.6 \\
\hline Brainstem function & 5.4 & 3.4 \\
\hline Number of prior attacks & & \\
\hline$<2$ & $14(25.0)$ & $25(14.4)$ \\
\hline$\geq 2$ & $42(75.0)$ & $149(85.6)$ \\
\hline
\end{tabular}

Abbreviations: EDSS = Expanded Disability Status Scale; Gd+ = gadolinium enhancing; $\mathrm{mRS}=$ modified Rankin Scale.

Data are $\mathrm{n}(\%)$, unless otherwise stated.

\section{Classification of Evidence}

This study provides Class II evidence that, relative to placebo, participants with NMOSD receiving inebilizumab had a lower risk of 3-month CDP from any point in the RCP (hazard ratio [HR]: 0.375; 95\% CI: 0.148-0.952; $p=0.0390$ ). Inebilizumab-treated participants experienced a lower risk of EDSS worsening relative to those receiving placebo, with no differences in treatment effect size (OR; 95\% CI; interaction test $p$ value) seen among subgroups dichotomized according to baseline EDSS score (EDSS <5: 0.375 [0.155-0.906]; EDSS $\geq 5: 0.360[0.109-1.191] ; p=0.8908)$, attack history ( $<2$ attacks: $0.503[0.082-3.081]$; $\geq 2$ attacks: 0.322 $[0.150-0.692] ; p=0.6215)$, or disease duration $(<5$ years: 0.417 [0.193-0.899]; $\geq 5$ years: $0.213[0.038-1.187] ; p=0.5342)$, and were more likely to report lower mRS disability scores at the end of the RCP (WMWodds: 1.663; 95\% CI: 1.195-2.385; $p=0.0023)$.

\section{Data Availability}

Anonymized/deidentified data sets for defined study outcomes will be made available on reasonable request. Proposals should be directed to katze@vielabio.com. Requestors will be required to sign a data access agreement. Requests will be considered up to 3 years following article publication.

\section{Results}

\section{Study Participants}

A total of 230 participants received study medication (inebilizumab: $\mathrm{n}=174$; placebo: $\mathrm{n}=56$ ). Baseline demographics and characteristics were generally similar between treatment groups (table). Most participants were women $(\mathrm{n}=209$; $90.9 \%)$. The mean (SD) age was 42.9 (12.2) years. The mean (SD) disease duration was 2.4 (3.3) years in the inebilizumab 


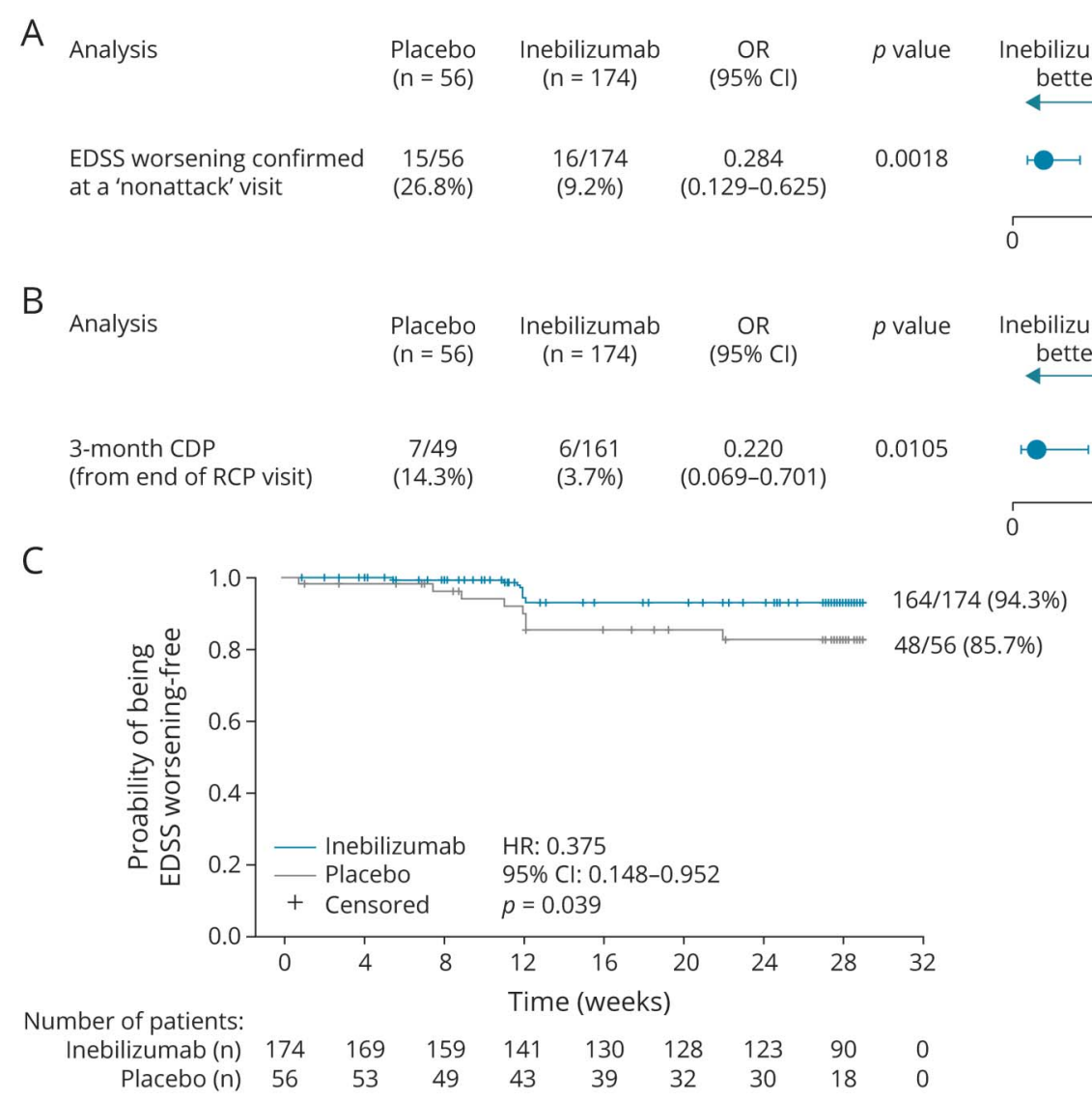

(A) EDSS worsening at the end of the RCP using nonattack visit data. Analysis conducted by using EDSS values from OLP month 3 for those participants who had AC-determined attack at their end of RCP visit (placebo: $n=15$; inebilizumab: $n=14$ ). End of the RCP visit data were used for those who did not have attacks (placebo: $n=0$; inebilizumab: $n=2$ ). (B) Three-month CDP from the end of the RCP visit. Analysis conducted for the subgroup of patients with EDSS worsening at the last RCP visit irrespective of whether participants had attacks, confirmed at OLP month 3 (placebo: $7 / 7$ had attacks; inebilizumab: $2 / 6$ had attacks). (C) Kaplan-Meier plot of the risk of 3-month CDP from any point in the RCP. None of those randomized to placebo with EDSS worsening at the last RCP visit had a subsequent attack in the first 3 months of OLP. Only 1 participant randomized to inebilizumab with EDSS worsening at the last RCP visit had a subsequent attack within the 3-month OLP window. AC = adjudication committee; CDP = confirmed disability progression; EDSS = Expanded Disability Status Scale; $\mathrm{HR}=$ hazard ratio; OLP = open-label period; RCP = randomized controlled period.

group and 2.8 (3.5) years in the placebo group. The median (range) EDSS score at baseline was $3.5(0-8.0)$ for participants receiving inebilizumab and 4.0 (1.0-8.0) for those receiving placebo. The proportion of participants with an EDSS score of 5 or above at baseline was $23.6 \%$ in the inebilizumab group and $28.6 \%$ in the placebo group. The median (range) mRS score at baseline was $2(0-5)$ in both treatment groups.

\section{EDSS Outcomes}

The proportion of participants who had protocol-defined EDSS worsening at the end of the RCP (at 28 weeks/ occurrence of adjudicated attack) was lower with inebilizumab treatment $(15.5 \%[27 / 174])$ than with placebo $(33.9 \%$ [19/56]; OR: 0.370; 95\% CI: 0.185-0.739; $p=0.0049) .^{15}$ The number needed to treat (NNT) with inebilizumab to prevent 1 case of EDSS score worsening at 28 weeks was 6 .

The trial design for N-MOmentum implemented an eventbased study design: for those participants who experienced an attack, this likely means that the EDSS score for these participants was measured at its likely maximum value, compared with the baseline level of disability experienced by participants.

Reduced risk of EDSS worsening with inebilizumab was, however, confirmed in 3 post hoc analyses. In the first analysis (designed to mitigate the confounding effect of analyzing EDSS scores during acute attacks by substituting a post attack, convalescent EDSS score for those with attacks), the risk of EDSS worsening was lower in the inebilizumab arm relative to the placebo arm (OR: 0.284; 95\% CI: 0.129-0.625; $p=0.0018$ ) (figure 1A).

The 2 other post hoc analyses were performed to evaluate 3-month CDP. The proportion of participants with 3-month CDP at the end of the RCP was lower in the inebilizumab arm (OR: 0.220; 95\% CI: 0.069-0.701; $p=0.0105$ ) (figure 1B). Importantly, results were similar when 3-month CDP was defined as EDSS worsening from any time during the RCP and confirmed at least 3 months later: the proportion of 


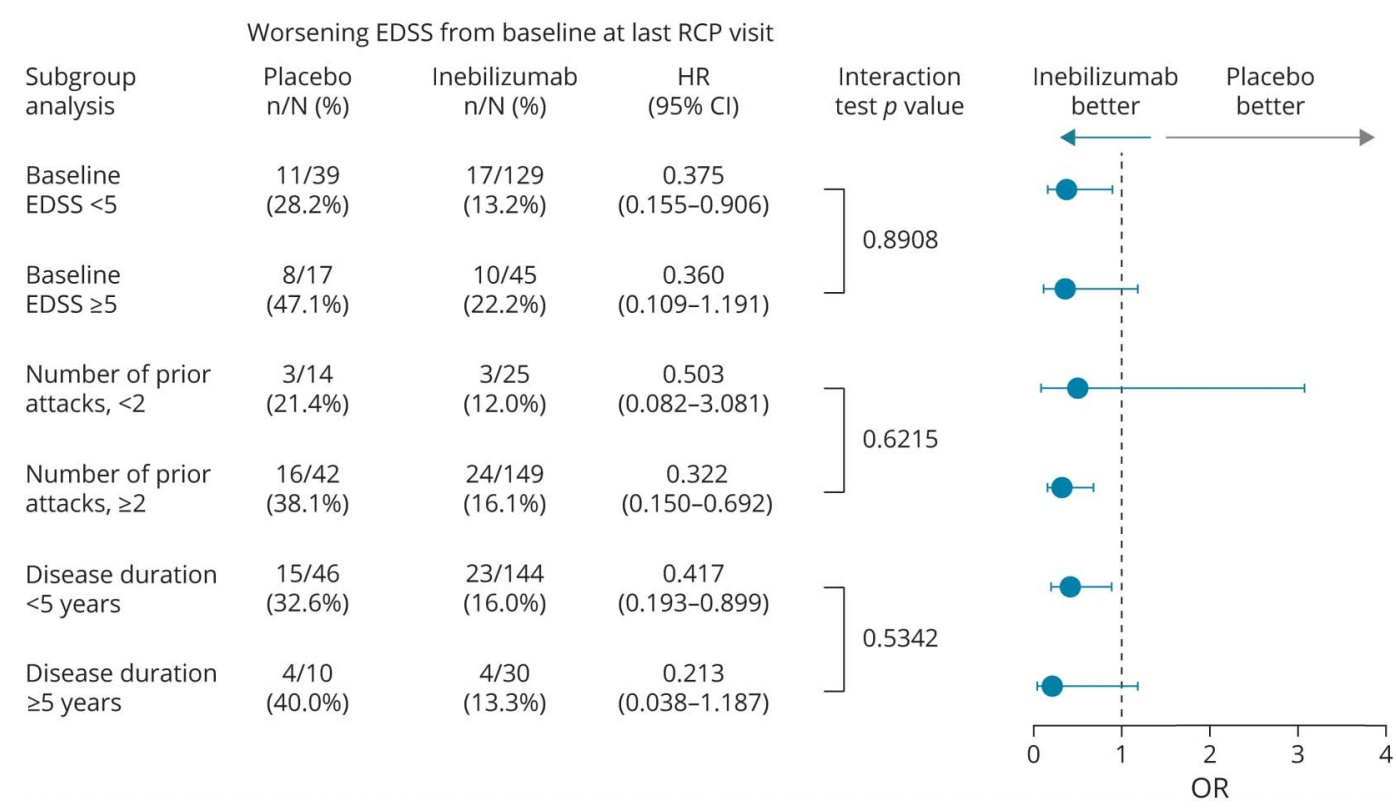

Figure shows the risk of EDSS score worsening from baseline to the end of the RCP. EDSS = Expanded Disability Status Scale; HR = hazard ratio; RCP = randomized controlled period.

participants with 3-month CDP during the RCP was $14.3 \%$ with placebo and $5.7 \%$ with inebilizumab $(62.5 \%$ risk reduction; HR: 0.375 ; 95\% CI: $0.148-0.952 ; p=0.0390)$ (figure 1C).

Of 27 participants receiving inebilizumab who had worsening in EDSS score at the end of the RCP, $51.9 \%(14 / 27)$ had adjudicated attacks, $3.7 \%(1 / 27)$ had principal investigator (PI)-determined, nonadjudicated attack, and 44.4\% (12/27) had no attack. Of 19 placebo-treated participants who had EDSS score worsening, $78.9 \%(15 / 19)$ had adjudicated attacks, 5.3\% (1/19) had PI-determined, nonadjudicated attack, and $15.8 \%(3 / 19)$ had no attack. A similar proportion of participants in each arm had EDSS score worsening at the end of the RCP in the absence of any attack (inebilizumab: 6.9\% [12/174]; placebo: $5.4 \%[3 / 56])$.

The prespecified subgroup analyses of EDSS score worsening showed a consistently reduced risk in inebilizumab-treated participants compared with placebo, regardless of the baseline EDSS score, number of previous attacks, or disease duration, with no significant differences in treatment effect seen with inebilizumab observed among these subgroups (figure 2).

In the first year of the OLP, when all participants received inebilizumab, the mean change in EDSS scores decreased in participants originally treated with inebilizumab and in those originally treated with placebo (figure 3A). The curves for mean change in EDSS were approximately parallel during the OLP in the 2 treatment arms and did not converge (figure 3A). Mean changes in EDSS scores for the subgroups with and without attacks during the RCP are shown in figure 3, B and $\mathrm{C}$.

\section{mRS Outcomes}

The prespecified analysis showed that mRS outcomes at the end of the RCP were better with inebilizumab than with placebo treatment in $51.5 \%$ of cases, equal in $21.9 \%$ of cases, and worse in $26.6 \%$ of cases. Participants treated with inebilizumab were $66.3 \%$ more likely to report less disability at the end of the RCP compared with placebo treatment (OR: 1.663; 95\% CI: 1.195-2.385; $p=0.0023$ ) (figure 4A). Similar proportions of participants had no symptoms or no significant disability ( $\mathrm{mRS}$ score $<2$ ) at baseline in the inebilizumab (46.6\%) and placebo (41.1\%) groups. By the end of the RCP, the proportion of participants without significant disability remained stable with inebilizumab (48.3\%), but fell with placebo (33.9\%) (figure 4B, C).

\section{Attack Incidence, Severity, Recovery, and Use of Rescue Medication}

None of those randomized to placebo with EDSS worsening at the last RCP visit had a subsequent attack in the first 3 months of OLP. Only 1 participant randomized to inebilizumab with EDSS worsening at the last RCP visit had a subsequent attack within the 3-month OLP window.

Attack severity, measured by the modified OSIS scale, ${ }^{21,22}$ numerically favored inebilizumab treatment, with attack severity graded as major in $29 \%$ of inebilizumab attacks vs $45 \%$ of placebo attacks ( $p=0.35$; figure e-1A, links.lww.com/NXI/ A454). The degree of recovery from attacks was nominally 
A

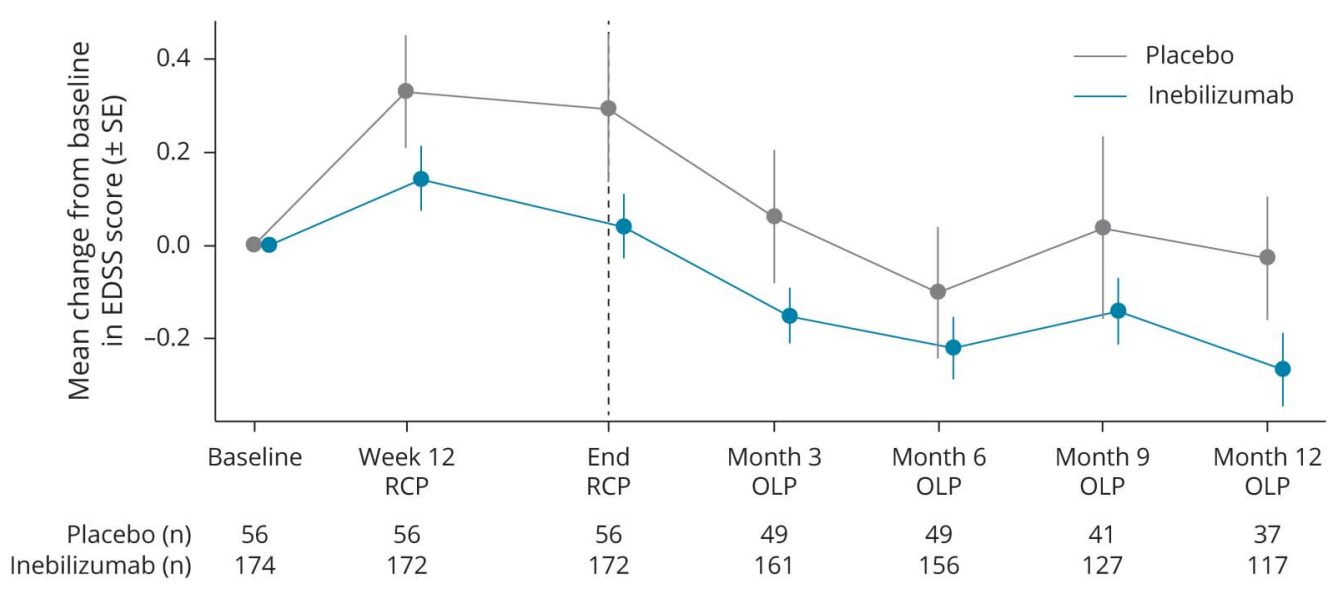

B

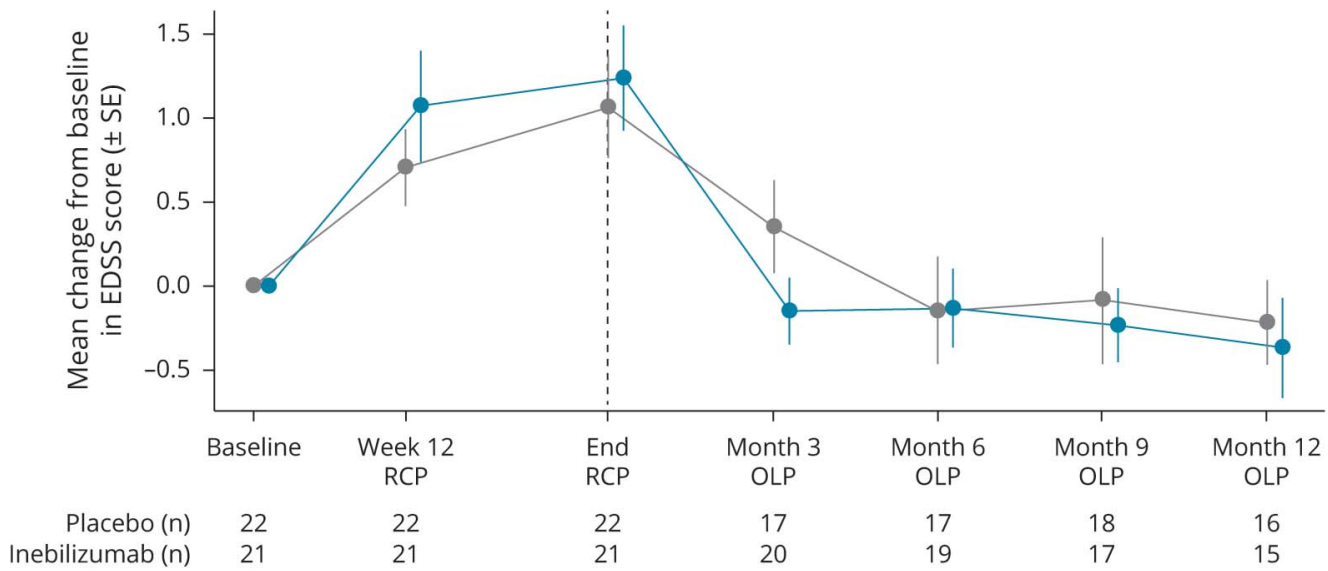

C

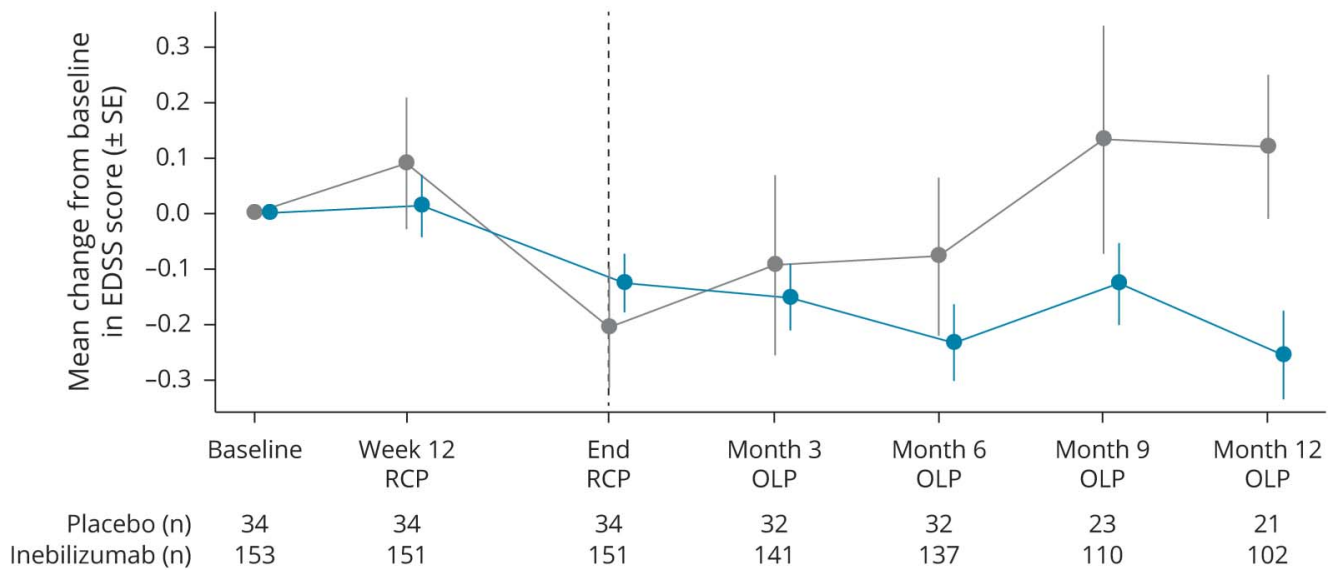

(A) Overall population. (B) Participants with attacks in the RCP. (C) Participants without attacks in the RCP. EDSS = Expanded Disability Status Scale; OLP = openlabel period; RCP = randomized controlled period.

better with inebilizumab (figure e-1B), although this analysis is confounded by differences in attack severity.

Rescue therapy was allowed according to the N-MOmentum study protocol and was administered at the discretion of the study investigator. Steroid therapy was used in the vast majority of attacks, with only 1 participant (randomized to inebilizumab) who did not receive steroid treatment. Most received IV steroid treatment (34 participants received $1,000 \mathrm{mg}$ doses; 3 received $500 \mathrm{mg}$ doses), with 1 participant receiving a $1,000 \mathrm{mg}$ dose of oral steroids. Conversely, plasmapheresis was used to treat a minority of attacks and was administered to a similar 

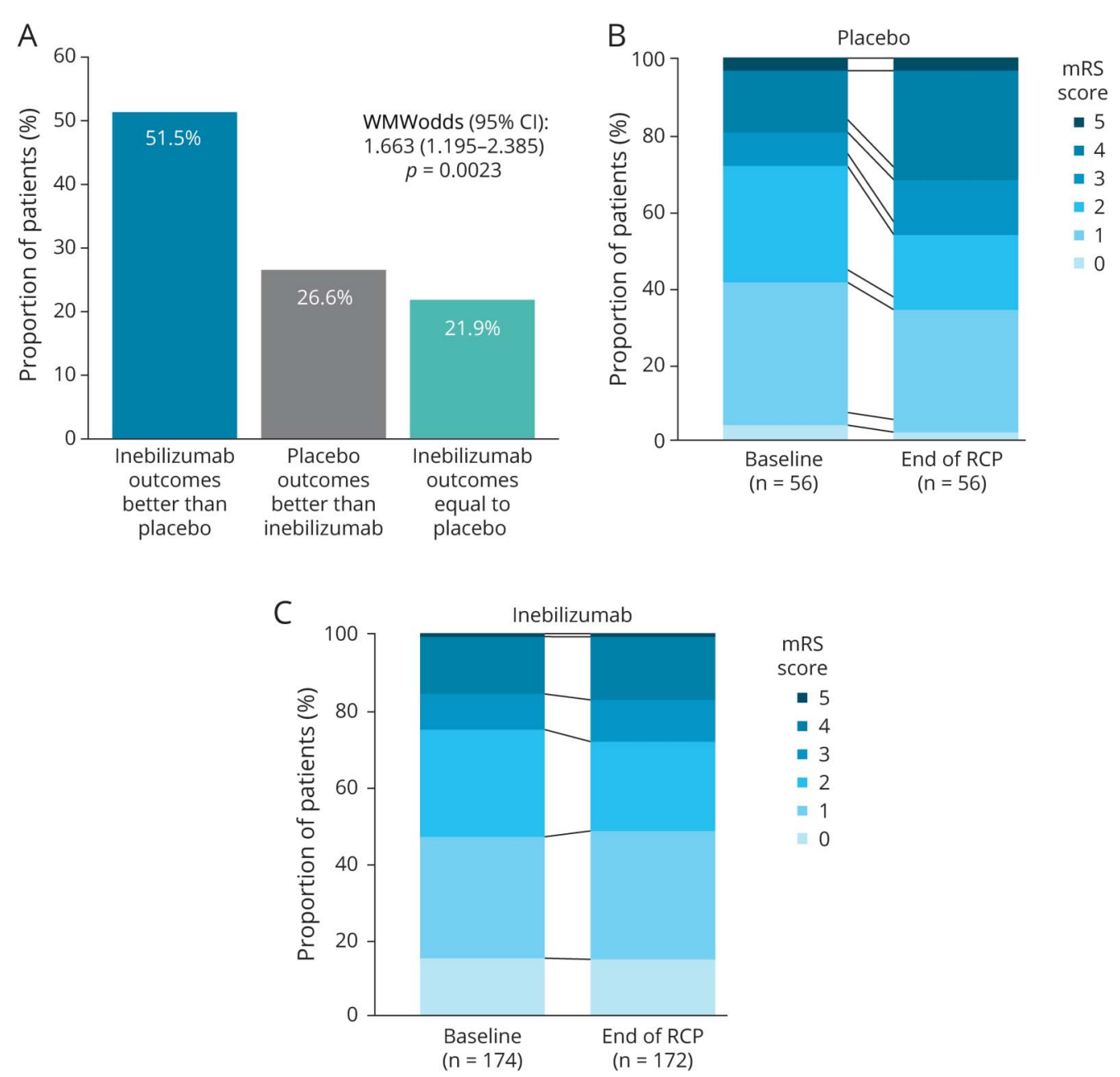

(A) Treatment effect based on the mRS score during the RCP. (B) Distribution of mRS scores at baseline and at the last RCP visit in patients treated with placebo. (C) Distribution of mRS scores at baseline and at the last RCP visit in patients treated with inebilizumab. $\mathrm{mRS}=$ modified Rankin Scale; $\mathrm{RCP}=\mathrm{randomized}$ controlled period; WMWodds = Wilcoxon-Mann-Whitney odds.

number of participants in each treatment group (6/22 attacks in the placebo group [27.3\%]; 5/21 in the inebilizumab group [23.8\%]). As such, the rescue therapies used in the treatment of acute attacks were similar in both the placebo and inebilizumab groups and are unlikely to have influenced the observed differences in disability outcomes.

\section{Discussion}

NMOSD is associated with substantial morbidity and mortality. A review of over 100 patients with NMOSD reported that $18 \%$ developed permanent visual disability, $34 \%$ developed permanent motor disability, and $23 \%$ became wheelchair dependent at a median follow-up of 75 months after disease onset. ${ }^{25}$ A retrospective analysis of 175 patients with NMOSD showed that disability accrued over time, with a median annualized increase in the EDSS score of 0.65 in patients with a disease duration of $\geq 12$ months. ${ }^{26}$ The median EDSS score was 5 at 58 months (median) after disease onset, indicating impaired ambulation; the median disease duration until patients required a walking aid (EDSS score of 6 or 6.5 ) was 94 months. ${ }^{26}$ Mortality in the 2 studies was $9 \%$ and $6 \%$ of patients at a median follow-up of 99 and 116 months, respectively. ${ }^{25,26}$

Several factors influence clinical outcomes in patients with NMOSD. Ethnicity, onset age, and onset attack type appear to affect disease outcomes. ${ }^{25,27-29}$ Higher attack frequency predicts severe motor disabilities, ${ }^{28}$ as does delay in diagnosis/preventive treatment. ${ }^{29}$ Here, we found that the impact of inebilizumab treatment was not influenced by baseline participant characteristics (figure 2).

The current approved treatment options for patients with NMOSD are limited. Inebilizumab is approved in the United States for treatment of AQP4-IgG-seropositive adults with NMOSD. $^{30}$ The results described here confirm that inebilizumab reduces the risk of disability worsening in 
individuals with NMOSD. The treatment effect is sustained across multiple subgroups, supporting a benefit of inebilizumab in a broad spectrum of patients with NMOSD. The NNT shows that only 6 inebilizumab-treated patients are needed to prevent 1 case of worsening disability after 6.5 months. Beneficial effects on disability measures were previously reported with azathioprine ${ }^{31}$ and rituximab, ${ }^{9,32}$ although evidence is limited to uncontrolled, observational studies. Rituximab provided larger reductions in the EDSS score from baseline when compared with azathioprine in a randomized, open-label study of NMOSD, ${ }^{33}$ but showed no difference to placebo in a double-blind study. ${ }^{34}$

Eculizumab, a terminal complement inhibitor, is also approved for the treatment of adults with AQP4-IgG-seropositive NMOSD. ${ }^{35,36}$ Eculizumab significantly reduced the risk of attack in a randomized, double-blind, placebo-controlled trial in AQP4-IgG-seropositive participants with NMOSD. ${ }^{11}$ However, no significant difference was observed between the groups for disability progression. ${ }^{11}$ Satralizumab, a humanized, anti-interleukin-6 receptor monoclonal antibody, also demonstrated reduction in attacks but no significant effects on disability. ${ }^{12}$ There is a possibility that the absence of significant impact of these 2 drugs on disability may be due to differences in mechanism of action, but differences in study design and lack of statistical power are more likely explanations.

As recently reviewed by Levy et al., ${ }^{37}$ attack rates cannot be compared directly between studies owing to the contrasting study designs. Differences in the use of attack criteria, attack adjudication, the censoring of attack events, and differing prior and onstudy concomitant therapy all combine to confound interstudy interpretation. The difference in study designs may also be a factor with regard to disability outcomes. The increased power afforded by the number of patients enrolled in N-MOmentum, as well as the mechanism used to control for multiplicity testing in the key secondary end points, may have made N-MOmentum more sensitive to differences in disability outcomes. It should also be considered that the EDSS is known to be dominated by ambulation ${ }^{18}$ and may be less sensitive to disability induced by changes in visual or cognitive function. Use of a broader range of metrics, such as the mRS, may be useful to detect effects on disability in future studies of NMOSD.

Methods for analyzing disability in NMOSD were adapted from MS trials. Pivotal MS trials typically measure EDSS scores over 2 or more years, and 3-month CDP is commonly reported. Applying these techniques to NMOSD studies is challenging due to differences in study design. To reduce risks related to placebo exposure, the N-MOmentum study offered inebilizumab to participants following adjudicated attacks. As a consequence, analysis of 3-month CDP is confounded by inebilizumab treatment.

This article presents additional analyses to address the limitations of the study design and the confounding influence of inebilizumab treatment. The post hoc analyses presented in the article validate the outcomes despite the limitations of trial design used in the N-MOmentum study. The predefined analysis of disability worsening as the secondary end point of the study, combined with the 3 post hoc analyses done to provide a 3-month CDP, establishes a clear benefit of inebilizumab treatment on disability worsening. Moreover, the bias on 3-month CDP introduced by inebilizumab treatment following attacks, or at the end of the RCP, would actually reduce the estimate of the impact of inebilizumab on disability and therefore is unlikely to affect the validity of the CDP analyses. In addition, the ORs calculated as part of the original study analysis ${ }^{15}$ compared favorably with those calculated as part of the post hoc analyses $(0.370$ vs $0.220-0.375$, respectively) and provide further confidence in these findings.

The benefit of inebilizumab on disability outcomes was underscored by data collected during the OLP. With 12 months of open-label treatment, net improvement in the EDSS score was observed in both treatment groups. Participants randomized to inebilizumab had lower EDSS scores compared with baseline. Participants initially receiving placebo experienced EDSS score worsening by the end of the RCP, but EDSS scores improved following 1 year of inebilizumab treatment (figure 3A). Improvement in disability may therefore occur in some participants treated with inebilizumab. Another important observation is that by OLP month 12 , disability scores in participants randomized to placebo remained higher than those randomized to inebilizumab, suggesting that even a 6-month delay in initiation of treatment may persistently affect disability.

The mRS analysis supports the conclusion that inebilizumab treatment reduces the risk of disability worsening in NMOSD (figure 4). The fact that inebilizumab had an impact on the mRS is particularly noteworthy as the mRS strictly measures gross disability, as opposed to neurologic impairments that may contribute to disability and which are measured by the lower ranges of the EDSS scale.

Inebilizumab might also lessen NMOSD attack severity (figure e-1, links.lww.com/NXI/A454) through a reduction in inflammatory damage during attacks. This hypothesis is consistent with the observation that serum glial fibrillary acidic protein, a marker of astrocyte damage, increased to a lesser extent during NMOSD attacks in inebilizumab-treated participants compared with placebo-treated individuals. ${ }^{38}$

Although EDSS score worsening was associated with an adjudicated attack in most cases, some participants experienced EDSS score worsening without an attack. There are several possible causes of EDSS score worsening in the absence of an adjudicated attack, including occurrence of a nonadjudicated attack, fluctuation in signs and symptoms, measurement variability, and attack-independent CNS injury. In 2/17 (11.8\%) cases of EDSS score worsening, the participants experienced an attack that did not meet adjudication criteria, and both were MRI negative. A similar proportion of participants in the 2 treatment arms had EDSS score worsening at the end of the RCP in the absence of attacks (inebilizumab: 6.9\%; placebo: $5.4 \%$ ). This may represent the approximate 
rate of events that are attributable to fluctuation in symptoms or measurement variability. Another possible explanation for EDSS score worsening in the absence of attacks is the accumulation of subclinical injury. Subclinical demyelination, ${ }^{5}$ cervical spinal cord atrophy, ${ }^{6}$ retinal pathology, ${ }^{7,39,40}$ and changes in visual evoked potential findings have been reported in NMOSD. ${ }^{41}$

The study had several limitations. First, the design limited evaluation of long-term disability outcomes by treatment arm. Second, the EDSS was developed and validated for use in MS and, despite clinical overlap, the EDSS was not previously validated in NMOSD. Furthermore, at higher ranges of the scale, the EDSS is primarily a measure of walking ability. Consequently, it likely has low sensitivity for detecting neurologic worsening unrelated to ambulation (e.g., optic nerve or brainstem injury) and hence could underestimate the rate of important disability worsening in nonambulatory participants. In addition, standard measures of EDSS score changes such as those used in studies of MS are not possible in the time to event design used in this study, which was required for the ethical use of a placebo control. ${ }^{15,16}$ With 3 treatments now approved for NMOSD, study designs including a placebo arm will no longer be required. Future study designs can therefore be longer, with EDSS and other disability scores measured in a more controlled manner.

In conclusion, these analyses demonstrated that compared with placebo, inebilizumab improves disability outcomes in individuals with NMOSD. Inebilizumab showed a consistent effect in reducing the risk of disability worsening compared with placebo, as measured by the EDSS or $\mathrm{mRS}$ score, regardless of baseline disability status, attack history, or disease duration, underlining the positive effect of inebilizumab on disability in participants with NMOSD.

\section{Acknowledgment}

The authors thank all the participants of the N-MOmentum trial. This article was submitted on behalf of the principal investigators of the N-MOmentum study group, who administered the clinical trial. Editing assistance was provided by Oxford PharmaGenesis Ltd.

\section{Study Funding}

The N-MOmentum trial was funded by MedImmune and Viela Bio. Viela Bio supported the development of this article, provided data analyses according to the direction of the authors, and paid for medical writing support, provided by Oxford PharmaGenesis Ltd.

\section{Disclosure}

R. Marignier serves on scientific advisory boards for MedImmune and Viela Bio and has received funding for travel and honoraria from Biogen Idec, Merck Serono, Novartis, Roche, Sanofi Genzyme, Teva, and Viela Bio. J.L. Bennett reports payment for study design/consultation from MedImmune/ Viela Bio, personal fees from AbbVie, Alexion, Chugai, Clene Nanomedicine, Genentech, Genzyme, Mitsubishi Tanabe
Pharma, Reistone Bio, and Roche, grants and personal fees from EMD Serono and Novartis, and grants from the GuthyJackson Charitable Foundation, Mallinckrodt, and the NIH and has a patent for Aquaporumab issued. H.J. Kim has received a grant from the National Research Foundation of Korea and consultancy/speaker fees or research support from Alexion, Aprilbio, Celltrion, Eisai, HanAll BioPharma, MDimune, Merck Serono, Novartis, Sanofi Genzyme, TevaHandok, and Viela Bio; serves on a steering committee for MedImmune/Viela Bio; and is a coeditor for the Multiple Sclerosis Journal and an associated editor for the Journal of Clinical Neurology. B.G. Weinshenker receives payments for serving as chair of attack adjudication committees for clinical trials in NMOSD for Alexion, MedImmune, and Viela Bio; has consulted with Chugai, Genentech, Roche Pharmaceuticals, and Mitsubishi Tanabe Pharma regarding clinical trial design for NMOSD; and has a patent for NMO-IgG for diagnosis of neuromyelitis optica, with royalties paid by Hospices Civils de Lyon, MVZ Labor PD Dr. Volkmann und Kollegen GbR, Oxford University, and RSR. S.J. Pittock reports grants, personal fees, and nonfinancial support from Alexion Pharmaceuticals, Inc., grants from Autoimmune Encephalitis Alliance and Grifols, grants, personal fees, nonfinancial support, and other from MedImmune and Viela Bio, consulting support from Astellas, and personal fees for consulting services from UCB and has a patent \# 9,891,219 (Application \# 12-573942) "Methods for Treating Neuromyelitis Optica (NMO) by Administration of Eculizumab to an individual that is Aquaporin-4 (AQP4)-IgG Autoantibody positive". D. Wingerchuk reports personal fees from Arcus Medica, Biogen, Celgene, Genentech, MedImmune, Novartis, Reistone Bio, TG Therapeutics, and Third Rock Ventures, research support paid to Mayo Clinic by Alexion Pharmaceuticals and Terumo BCT, and serves on a clinical trial adjudication committee for MedImmune and Viela Bio. K. Fujihara serves on scientific advisory boards for Alexion, Bayer Schering, Biogen Idec, Chugai, MedImmune, Merck Serono, Mitsubishi Tanabe Pharma, Nihon Pharmaceutical, Novartis, Ono, and Viela Bio and has received funding for travel and speaker honoraria from Asahi Kasei Medical, Astellas, Bayer Schering, Biogen Idec, Daiichi Sankyo, Dainippon Sumitomo, Eisai, Mitsubishi Tanabe Pharma, Nihon Pharmaceutical, Novartis, and Takeda and research support from Asahi Kasei Medical, Bayer Schering, Biogen Idec, ChemoSero-Therapeutic Research Institute, Chugai, Genzyme Japan, the Ministry of Education, Culture, Sports, Science and Technology of Japan, the Ministry of Health, Welfare and Labor of Japan, Mitsubishi Tanabe Pharma, Nihon Pharmaceutical, Ono, Teijin, and Teva. F. Paul has received research support, speaker honoraria, and travel reimbursement from Bayer, Biogen Idec, Merck Serono, Novartis, Sanofi Genzyme, and Teva; is supported by the German Competence Network for Multiple Sclerosis and the German Research Foundation (DFG Exc 257); received travel reimbursement from the Guthy-Jackson Charitable Foundation; and serves on the steering committee of the OCTIMS study sponsored by Novartis. G.R. Cutter has 
received personal fees for participation on Data and Safety Monitoring Boards from AstraZeneca, Avexis Pharmaceuticals, Biolinerx, Brain Storm Cell Therapeutics, Bristol-Meyers Squibb/Celgene, CSL Behring, Galmed Pharmaceuticals, Horizon Pharmaceuticals, Hisun Pharmaceuticals, Mapi Pharmaceuticals LTD, Merck, Merck/Pfizer, Opko Biologics, OncoImmune, Neurim, Novartis, Orphazyme, SanofiAventis, Reata Pharmaceuticals, Teva pharmaceuticals, Viela Bio, Vivus, NHLBI (Protocol Review Committee), and NICHD (OPRU oversight committee) and personal fees for consulting or advisory board participation from Biodelivery Sciences International, Biogen, Click Therapeutics, Genzyme, Genentech, GW Pharmaceuticals, Immunic, Klein-Buendel Incorporated, MedImmune, MedDay, Neurogenesis LTD, Novartis, Osmotica Pharmaceuticals, Perception Neurosciences, Recursion/Cerexis Pharmaceuticals, Roche, and TG Therapeutics. G.R. Cutter is employed by the University of Alabama at Birmingham and is President of Pythagoras, Inc., a private consulting company based in Birmingham, AL. A.J. Green reports grants from Conrad N. Hilton Foundation and Tom Sherak MS Hope Foundation, other financial relationships (for activities as expert witness, associate editor, advisory board/steering committee participation, and end point adjudication) with Bionure, Inception Sciences, JAMA Neurology, MedImmune/Viela Bio, Mylan, Synthon, and Trims Pharma, and personal fees from and other financial relationships with Pipeline Therapeutics. O. Aktas reports grants from the German Ministry of Education and Research (BMBF) and the German Research Foundation (DFG), grants and personal fees from Bayer HealthCare, Biogen, Genzyme, Novartis, Teva, and Viela Bio, and personal fees from Almirall, MedImmune, Merck Serono, and Roche. H.-P. Hartung has received fees for consulting, speaking, and serving on steering committees from Bayer HealthCare, Biogen Idec, Celgene Receptos, CSL Behring, GeNeuro, Genzyme, MedDay, MedImmune, Merck Serono, Novartis, Roche, Sanofi, TG Therapeutics, and Viela Bio, with approval by the Rector of Heinrich Heine University Düsseldorf. F.D. Lublin reports personal fees from AbbVie, Acorda, Actelion, Apitope, Atara Biotherapeutics, Bayer HealthCare, Biogen and Biogen Idec, BrainStorm Cell Therapeutics, EMD Serono, Forward Pharma, GW Pharmaceuticals, Innate Immunotherapeutics, Jazz Pharmaceuticals, MedDay, MedImmune/Viela Bio, Novartis, Orion Biotech, Polpharma, Receptos/Celgene, Roche/Genentech, and TG Therapeutics, grants and personal fees from Sanofi Genzyme and Teva Neuroscience, and grants from Transparency Life Sciences. I.M. Williams is an employee of Oxford PharmaGenesis Ltd. J. Drappa, D. She, D. Cimbora, W. Rees, M. Smith, J.N. Ratchford, and E. Katz are employees of Viela Bio. B.A.C. Cree reports personal fees for consulting from Akili, Alexion, Atara, Biogen, EMD Serono, Novartis, Sanofi, and TG Therapeutics. Go to Neurology.org/NN for full disclosures.

\section{Publication History}

Received by Neurology: Neuroimmunology \& Neuroinflammation September 23, 2020. Accepted in final form January 8, 2021.

\section{Appendix 1 Authors}

\begin{tabular}{|c|c|c|}
\hline Name & Location & Contribution \\
\hline $\begin{array}{l}\text { Romain } \\
\text { Marignier, } \\
\text { MD, PhD }\end{array}$ & $\begin{array}{l}\text { Service de Neurologie } \\
\text { Sclérose en Plaques, } \\
\text { Pathologies de La Myéline et } \\
\text { Neuro-inflammation, Hôpital } \\
\text { Neurologique Pierre } \\
\text { Wertheimer, Hospices Civils } \\
\text { de Lyon, France }\end{array}$ & $\begin{array}{l}\text { Design/ } \\
\text { conceptualization of the } \\
\text { study; acquisition, } \\
\text { analysis/interpretation } \\
\text { of data; and drafting/ } \\
\text { revising the manuscript } \\
\text { for intellectual content }\end{array}$ \\
\hline
\end{tabular}

\begin{tabular}{ll}
\hline Jeffrey L. & University of Colorado School \\
Bennett, MD, & of Medicine, Anschutz Medical
\end{tabular}

Bennett, MD, of Medicine, Anschutz Medica PhD Campus, Aurora

\section{Design/}

conceptualization of the study; acquisition, analysis/interpretation of data; and drafting/ revising the manuscript for intellectual content

\begin{tabular}{ll}
\hline Ho Jin Kim, & Research Institute and \\
MD, PhD & Hospital of National Cancer \\
& Center, Goyang South Korea
\end{tabular}

Design/

conceptualization of the study; acquisition, analysis/interpretation of data; and drafting/ revising the manuscript for intellectual content

\begin{tabular}{lll}
\hline $\begin{array}{l}\text { Brian G. } \\
\text { Weinshenker, } \\
\text { MD }\end{array}$ & Mayo Clinic, Rochester, MN & $\begin{array}{l}\text { Design/ } \\
\text { conceptualization of the } \\
\text { study; acquisition, } \\
\text { analysis/interpretation } \\
\text { of data; and drafting/ } \\
\text { revising the manuscript } \\
\text { for intellectual content }\end{array}$ \\
& $\begin{array}{l}\text { Design/ } \\
\text { conceptualization of } \\
\text { the study; acquisition, } \\
\text { Pittock, MD }\end{array}$ & $\begin{array}{l}\text { analysis/ } \\
\text { interpretation of data; } \\
\text { and drafting/revising } \\
\text { the manuscript for }\end{array}$ \\
& & intellectual content
\end{tabular}

\begin{tabular}{lll}
\hline Dean & Mayo Clinic, Scottsdale, AZ & Design/ \\
Wingerchuk, & & conceptualization of \\
MD & the study; acquisition
\end{tabular}
the study; acquisition, analysis/ interpretation of data; and drafting/revising the manuscript for intellectual content

\begin{tabular}{ll}
\hline Kazuko & Department of Multiple \\
Fujihara, MD & Sclerosis Therapeutics, \\
& Fukushima Medical University \\
& and Multiple Sclerosis and \\
& Neuromyelitis Optica Center, \\
& Southern Tohoku Research \\
& Institute for Neuroscience, \\
& Koriyama, Japan
\end{tabular}

Design/

conceptualization of the study; acquisition, analysis/

interpretation of data; and drafting/revising the manuscript for intellectual content

\begin{tabular}{|c|c|c|}
\hline $\begin{array}{l}\text { Friedemann } \\
\text { Paul, MD }\end{array}$ & $\begin{array}{l}\text { Experimental and Clinical } \\
\text { Research Center, Max } \\
\text { Delbrück Center for Molecular } \\
\text { Medicine and } \\
\text { Charité-Universitätsmedizin } \\
\text { Berlin, Germany }\end{array}$ & $\begin{array}{l}\text { Design/ } \\
\text { conceptualization of } \\
\text { the study; acquisition, } \\
\text { analysis/ } \\
\text { interpretation of data; } \\
\text { and drafting/revising } \\
\text { the manuscript for } \\
\text { intellectual content }\end{array}$ \\
\hline $\begin{array}{l}\text { Gary R. Cutter, } \\
\text { PhD }\end{array}$ & $\begin{array}{l}\text { University of Alabama at } \\
\text { Birmingham }\end{array}$ & $\begin{array}{l}\text { Design/ } \\
\text { conceptualization of } \\
\text { the study; acquisition, } \\
\text { analysis/ } \\
\text { interpretation of data; } \\
\text { and drafting/revising } \\
\text { the manuscript for } \\
\text { intellectual content }\end{array}$ \\
\hline
\end{tabular}


Appendix 1 (continued)

\begin{tabular}{ll}
\hline Name & Location \\
\hline Ari J. Green, & $\begin{array}{l}\text { UCSF Weill Institute for } \\
\text { MD, MCR }\end{array}$ \\
$\begin{array}{l}\text { Neurosciences, Department } \\
\text { of Neurology and Department } \\
\text { of Ophthalmology, University } \\
\text { of California San Francisco }\end{array}$
\end{tabular}

Contribution

Design/

conceptualization of

the study; acquisition,

analysis/interpretation

of data; and drafting/

revising the manuscript

for intellectual content

\begin{tabular}{ll}
\hline Orhan Aktas, & Medical Faculty, Heinrich \\
MD & Heine University, Düsseldorf, \\
& Germany
\end{tabular}

\section{Design/}

conceptualization of

the study; acquisition, analysis/interpretation of data; and drafting/ revising the manuscript for intellectual content

\begin{tabular}{ll}
\hline Hans-Peter & Medical Faculty, Heinrich \\
Hartung, MD & Heine University, Düsseldorf, \\
& Germany
\end{tabular}

Design/

conceptualization of the study; acquisition, analysis/interpretation of data; and drafting/ revising the manuscript for intellectual content

\begin{tabular}{ll}
\hline Fred D. Lublin, & Icahn School of Medicine at \\
MD & Mount Sinai, New York
\end{tabular}

Design/

conceptualization of the study; acquisition, analysis/interpretation of data; and drafting/ revising the manuscript for intellectual content

\begin{tabular}{lll}
\hline $\begin{array}{l}\text { Ian M. } \\
\text { Williams, PhD }\end{array}$ & $\begin{array}{l}\text { Oxford PharmaGenesis Ltd, } \\
\text { UK }\end{array}$ & $\begin{array}{l}\text { Interpretation of data } \\
\text { and drafting/revising } \\
\text { the manuscript for } \\
\text { intellectual content }\end{array}$
\end{tabular}

\begin{tabular}{lll}
\hline Jorn Drappa, & Viela Bio, Gaithersburg, MD & $\begin{array}{l}\text { Design/ } \\
\text { conceptualization of }\end{array}$ \\
MD, PhD &
\end{tabular}
MD, PhD the study: acquisition, analysis/interpretation of data; and drafting/ revising the manuscript for intellectual content

\begin{tabular}{lll}
\hline $\begin{array}{l}\text { Dewei She, } \\
\text { PhD }\end{array}$ & Viela Bio, Gaithersburg, MD & $\begin{array}{l}\text { Design/ } \\
\text { conceptualization of } \\
\text { the study; acquisition, } \\
\text { analysis/interpretation } \\
\text { of data; and drafting/ } \\
\text { revising the manuscript } \\
\text { for intellectual content }\end{array}$ \\
\hline $\begin{array}{l}\text { Daniel } \\
\text { Cimbora, PhD }\end{array}$ & Viela Bio, Gaithersburg, MD & $\begin{array}{l}\text { Design/ } \\
\text { conceptualization of } \\
\text { the study; acquisition, } \\
\text { analysis/interpretation } \\
\text { of data; and drafting/ } \\
\text { revising the manuscript } \\
\text { for intellectual content }\end{array}$ \\
\hline
\end{tabular}

\begin{tabular}{ll}
\hline William Rees, Viela Bio, Gaithersburg, MD & Design/ \\
PhD & conceptualization of \\
& the study; acquisition, \\
& analysis/interpretation \\
& of data; and drafting/ \\
& revising the manuscript \\
& for intellectual content
\end{tabular}

\begin{tabular}{lll}
\hline Michael & Viela Bio, Gaithersburg, MD & Design/ \\
Smith, PhD & conceptualization of \\
& the study; acquisition, \\
& analysis/interpretation \\
& of data; and drafting/ \\
& revising the manuscript \\
& for intellectual content
\end{tabular}

Appendix 1 (continued)

\begin{tabular}{|c|c|c|}
\hline Name & Location & Contribution \\
\hline $\begin{array}{l}\text { John N. } \\
\text { Ratchford, MD }\end{array}$ & Viela Bio, Gaithersburg, MD & $\begin{array}{l}\text { Design/ } \\
\text { conceptualization of } \\
\text { the study; acquisition, } \\
\text { analysis/ } \\
\text { interpretation of data; } \\
\text { and drafting/revising } \\
\text { the manuscript for } \\
\text { intellectual content }\end{array}$ \\
\hline $\begin{array}{l}\text { Eliezer Katz, } \\
\text { MD }\end{array}$ & Viela Bio, Gaithersburg, MD & $\begin{array}{l}\text { Design/ } \\
\text { conceptualization of } \\
\text { the study; acquisition, } \\
\text { analysis/ } \\
\text { interpretation of data; } \\
\text { and drafting/revising } \\
\text { the manuscript for } \\
\text { intellectual content }\end{array}$ \\
\hline $\begin{array}{l}\text { Bruce A.C. } \\
\text { Cree, MD, } \\
\text { PhD, MAS }\end{array}$ & $\begin{array}{l}\text { UCSF Weill Institute for } \\
\text { Neurosciences }\end{array}$ & $\begin{array}{l}\text { Design/ } \\
\text { conceptualization of } \\
\text { the study; acquisition, } \\
\text { analysis/ } \\
\text { interpretation of data; } \\
\text { and drafting/revising } \\
\text { the manuscript for } \\
\text { intellectual content }\end{array}$ \\
\hline
\end{tabular}

\section{Appendix 2 Coinvestigators}

The N-MOmentum Study Investigators are listed at links.Iww.com/NXI/A453.

\section{References}

1. Wingerchuk DM, Lennon VA, Lucchinetti CF, Pittock SJ, Weinshenker BG. The spectrum of neuromyelitis optica. Lancet Neurol 2007;6:805-815.

2. Lucchinetti CF, Guo Y, Popescu BF, Fujihara K, Itoyama Y, Misu T. The pathology of an autoimmune astrocytopathy: lessons learned from neuromyelitis optica. Brain Pathol 2014;24:83-97.

3. Pittock SJ, Lennon VA, Krecke K, Wingerchuk DM, Lucchinetti CF, Weinshenker BG. Brain abnormalities in neuromyelitis optica. Arch Neurol 2006;63:390-396.

4. Jarius S, Wildemann B, Paul F. Neuromyelitis optica: clinical features, immunopathogenesis and treatment. Clin Exp Immunol 2014;176:149-164.

5. Jeong IH, Choi JY, Kim SH, et al. Normal-appearing white matter demyelination in neuromyelitis optica spectrum disorder. Eur J Neurol 2017;24:652-658.

6. Ventura RE, Kister I, Chung S, Babb JS, Shepherd TM. Cervical spinal cord atrophy in NMOSD without a history of myelitis or MRI-visible lesions. Neurol Neuroimmunol Neuroinflamm 2016;3:e224

7. Jeong IH, Kim HJ, Kim NH, Jeong KS, Park CY. Subclinical primary retinal pathology in neuromyelitis optica spectrum disorder. J Neurol 2016;263:1343-1348.

8. Ringelstein M, Harmel J, Zimmermann $\mathrm{H}$, et al. Longitudinal optic neuritis-unrelated visual evoked potential changes in NMO spectrum disorders. Neurology 2020;94:e407-e418.

9. Damato V, Evoli A, Iorio R. Efficacy and safety of rituximab therapy in neuromyelitis optica spectrum disorders: a systematic review and meta-analysis. JAMA Neurol 2016;73:1342-1348.

10. Espiritu AI, Pasco PMD. Efficacy and tolerability of azathioprine for neuromyelitis optica spectrum disorder: a systematic review and meta-analysis. Mult Scler Relat Disord 2019;33:22-32.

11. Pittock SJ, Berthele A, Fujihara K, et al. Eculizumab in aquaporin-4-positive neuromyelitis optica spectrum disorder. N Engl J Med 2019;381:614-625.

12. Yamamura T, Kleiter I, Fujihara K, et al. Trial of satralizumab in neuromyelitis optica spectrum disorder. N Engl J Med 2019;381:2114-2124.

13. Bennett JL, O'Connor KC, Bar-Or A, et al. B lymphocytes in neuromyelitis optica. Neurol Neuroimmunol Neuroinflamm 2015;2:e104.

14. Hausser-Kinzel S, Weber MS. The role of B cells and antibodies in multiple sclerosis, neuromyelitis optica, and related disorders. Front Immunol 2019;10:201.

15. Cree BAC, Bennett JL, Kim HJ, et al. Inebilizumab for the treatment of neuromyelitis optica spectrum disorder (N-MOmentum): a double-blind, randomised placebocontrolled phase 2/3 trial. Lancet 2019;394:1352-1363.

16. Cree BA, Bennett JL, Sheehan M, et al. Placebo-controlled study in neuromyelitis optica-Ethical and design considerations. Mult Scler 2016;22:862-872.

17. Wingerchuk DM, Lennon VA, Pittock SJ, Lucchinetti CF, Weinshenker BG. Revised diagnostic criteria for neuromyelitis optica. Neurology 2006;66:1485-1489. 
18. Kurtzke JF. Rating neurologic impairment in multiple sclerosis: an expanded disability status scale (EDSS). Neurology 1983;33:1444-1452.

19. van Swieten JC, Koudstaal PJ, Visser MC, Schouten HJ, van Gijn J. Interobserver agreement for the assessment of handicap in stroke patients. Stroke 1988;19:604-607.

20. D'Souza M, Yaldizli O, John R, et al. Neurostatus e-Scoring improves consistency of Expanded Disability Status Scale assessments: a proof of concept study. Mult Scler 2017;23:597-603.

21. Wingerchuk DM, Hogancamp WF, O'Brien PC, Weinshenker BG. The clinical course of neuromyelitis optica (Devic's syndrome). Neurology 1999;53:1107-1114.

22. Pittock SJ, Lennon VA, McKeon A, et al. Eculizumab in AQP4-IgG-positive relapsing neuromyelitis optica spectrum disorders: an open-label pilot study. Lancet Neurol 2013;12:554-562.

23. Churilov L, Arnup S, Johns H, et al. An improved method for simple, assumption-free ordinal analysis of the modified Rankin Scale using generalized odds ratios. Int J Stroke 2014;9:999-1005.

24. Divine G, Norton HJ, Hunt R, Dienemann J. Statistical grand rounds: a review of analysis and sample size calculation considerations for Wilcoxon tests. Anesth Analg 2013;117:699-710.

25. Kitley J, Leite MI, Nakashima I, et al. Prognostic factors and disease course in aquaporin-4 antibody-positive patients with neuromyelitis optica spectrum disorder from the United Kingdom and Japan. Brain 2012;135:1834-1849.

26. Jarius S, Ruprecht K, Wildemann B, et al. Contrasting disease patterns in seropositive and seronegative neuromyelitis optica: a multicentre study of 175 patients. J Neuroinflammation 2012;9:14.

27. Palace J, Lin DY, Zeng D, et al. Outcome prediction models in AQP4-IgG positive neuromyelitis optica spectrum disorders. Brain 2019;142:1310-1323.

28. Kim SH, Mealy MA, Levy M, et al. Racial differences in neuromyelitis optica spectrum disorder. Neurology 2018;91:e2089-e2099.

29. Mealy MA, Mossburg SE, Kim SH, et al. Long-term disability in neuromyelitis optica spectrum disorder with a history of myelitis is associated with age at onset, delay in diagnosis/preventive treatment, MRI lesion length and presence of symptomatic brain lesions. Mult Scler Relat Disord 2019;28:64-68.
30. Viela Bio. UPLINZA (Inebilizumab): Prescribing Information [online]. Available at: accessdata.fda.gov/drugsatfda_docs/label/2020/761142s000lbl.pdf. Accessed August 04,2020

31. Costanzi C, Matiello M, Lucchinetti CF, et al. Azathioprine: tolerability, efficacy, and predictors of benefit in neuromyelitis optica. Neurology 2011;77:659-666.

32. Cree BA, Lamb S, Morgan K, Chen A, Waubant E, Genain C. An open label study of the effects of rituximab in neuromyelitis optica. Neurology 2005;64:1270-1272.

33. Nikoo Z, Badihian S, Shaygannejad V, Asgari N, Ashtari F. Comparison of the efficacy of azathioprine and rituximab in neuromyelitis optica spectrum disorder: a randomized clinical trial. J Neurol 2017;264:2003-2009.

34. Tahara M, Oeda T, Okada K, et al. Safety and efficacy of rituximab in neuromyelitis optica spectrum disorders (RIN-1 study): a multicentre, randomised, double-blind, placebo-controlled trial. Lancet Neurol 2020;19:298-306.

35. Alexion Pharmaceuticals Inc. SOLIRIS (Eculizumab): Prescribing Information [online]. Available at: accessdata.fda.gov/drugsatfda_docs/label/2019/125166s431lbl.pdf. Accessed April 17, 2020.

36. Alexion Europe S.A.S. SOLIRIS (Eculizumab): Summary of Product Characteristics [online]. Available at: ema.europa.eu/en/documents/product-information/solirisepar-product-information_en.pdf. Accessed April 17, 2020.

37. Levy M, Fujihara K, Palace J. New therapies for neuromyelitis optica spectrum disorder. Lancet Neurol 2021;20:60-67.

38. Aktas $\mathrm{O}$, Smith M, Rees W, et al. Elevated serum glial fibrillary acidic protein (sGFAP) is associated with increased risk of neuromyelitis optica spectrum disorder attacks in the N-MOmentum randomised, masked, placebo-controlled clinical trial of inebilizumab. ECTRIMS Online Libr 2019;278649:P1609.

39. Oertel FC, Havla J, Roca-Fernandez A, et al. Retinal ganglion cell loss in neuromyelitis optica: a longitudinal study. J Neurol Neurosurg Psychiatry 2018;89:1259-1265.

40. Oertel FC, Kuchling J, Zimmermann H, et al. Microstructural visual system changes in AQP4-antibody-seropositive NMOSD. Neurol Neuroimmunol Neuroinflamm 2017; 4:e334.

41. Ringelstein M, Kleiter I, Ayzenberg I, et al. Visual evoked potentials in neuromyelitis optica and its spectrum disorders. Mult Scler 2014;20:617-620. 


\title{
Neurology \\ Neuroimmunology \& Neuroinflammation
}

\author{
Disability Outcomes in the N-MOmentum Trial of Inebilizumab in Neuromyelitis \\ Optica Spectrum Disorder \\ Romain Marignier, Jeffrey L. Bennett, Ho Jin Kim, et al. \\ Neurol Neuroimmunol Neuroinflamm 2021;8; \\ DOI 10.1212/NXI.0000000000000978
}

This information is current as of March 26, 2021

Neurol Neuroimmunol Neuroinflamm is an official journal of the American Academy of Neurology.

Published since April 2014, it is an open-access, online-only, continuous publication journal. Copyright

Copyright $\odot 2021$ The Author(s). Published by Wolters Kluwer Health, Inc. on behalf of the American

Academy of Neurology.. All rights reserved. Online ISSN: 2332-7812.

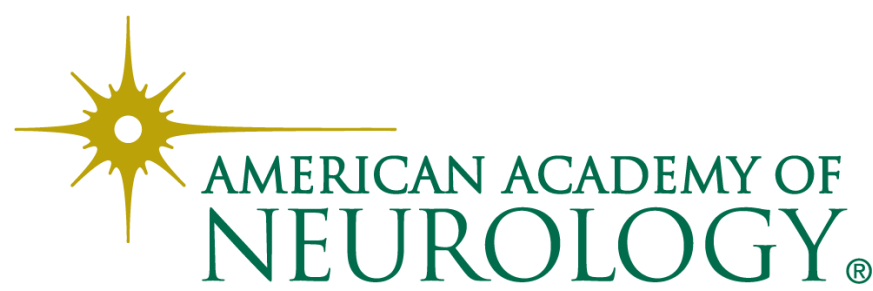




\section{Updated Information \& Services}

References

Citations

Subspecialty Collections

Permissions \& Licensing

Reprints including high resolution figures, can be found at: http://nn.neurology.org/content/8/3/e978.full.html

This article cites 38 articles, 5 of which you can access for free at: http://nn.neurology.org/content/8/3/e978.full.html\#\#ref-list-1

This article has been cited by 2 HighWire-hosted articles: http://nn.neurology.org/content/8/3/e978.full.html\#\#otherarticles

This article, along with others on similar topics, appears in the following collection(s):

All Clinical Neurology

http://nn.neurology.org//cgi/collection/all_clinical_neurology Autoimmune diseases

http://nn.neurology.org//cgi/collection/autoimmune_diseases Class II

http://nn.neurology.org//cgi/collection/class_ii

Clinical trials Randomized controlled (CŌNSORT agreement)

http://nn.neurology.org//cgi/collection/clinical_trials_randomized_cont rolled_consort_agreement

Devic's syndrome

http://nn.neurology.org//cgi/collection/devics_syndrome

Information about reproducing this article in parts (figures,tables) or in its entirety can be found online at:

http://nn.neurology.org/misc/about.xhtml\#permissions

Information about ordering reprints can be found online: http://nn.neurology.org/misc/addir.xhtml\#reprintsus

Neurol Neuroimmunol Neuroinflamm is an official journal of the American Academy of Neurology.

Published since April 2014, it is an open-access, online-only, continuous publication journal. Copyright

Copyright $\odot 2021$ The Author(s). Published by Wolters Kluwer Health, Inc. on behalf of the American

Academy of Neurology.. All rights reserved. Online ISSN: 2332-7812.

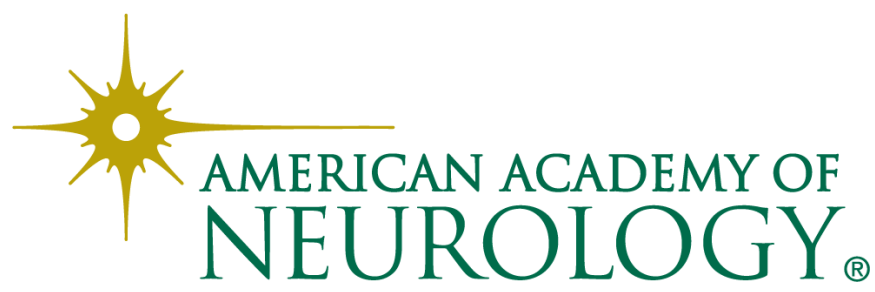

